\title{
Active Vibration Control of a Mechanical Servo High-speed Fine-Blanking Press
}

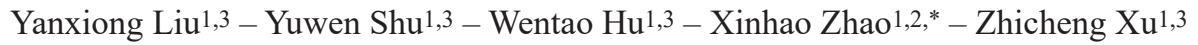 \\ ${ }^{1}$ Wuhan University of Technology, Hubei Key Laboratory of Advanced Technology of Automotive Components, China \\ ${ }^{2}$ Wuhan University of Technology, School of Materials Science and Engineering, China \\ ${ }^{3}$ Wuhan University of Technology, Hubei Collaborative Innovation Center for Automotive Components Technology, China
}

\begin{abstract}
The fine-blanking process as an advanced sheet metal forming process has been widely applied in industry. However, specially designed equipment is required for this process. In this paper, a novel mechanical servo high-speed fine-blanking press with the capacity of $3200 \mathrm{kN}$ is proposed, and the vibration control for this machine is researched to achieve the requirement of fine-blanked parts of high dimensional accuracy, since the vibration of the fine-blanking machine will cause the machining displacement error and reduce the machining accuracy. Self-adaptive feed-forward control is used to simulate the active vibration control of the mechanical fine-blanking machine. The vibration control principle of the fine-blanking machine is described, and the control algorithm is established. At the same time, the mechanical vibration model of the fine-blanking machine as the controlled object is established, and the parameters of the excitation input and the mechanical model are obtained by the fine-blanking finite element simulation and the experiments of the vibration measurement of the press. Finally, the numerical simulation and analysis of active vibration control based on MATLAB are carried out. The results show that the control effect is good, and the vibration response is effectively reduced, thus greatly increasing the processing accuracy, saving a significant amount of energy, and reducing the energy consumption and defective rate.
\end{abstract}

Keywords: active vibration control; mechanical vibration model; mechanical servo high-speed fine-blanking press; self-adaptive feedforward control

Highlights

- The mechanical vibration model of the fine-blanking machine tool is established.

- The dynamic model parameters of the mechanical fine-blanking machine are obtained by using finite element analysis and empirical formula.

- An adaptive feed-forward vibration controller for the fine-blanking machine is designed and applied to active vibration control of the fine-blanking machine.

- The vibration response of the whole machine has been effectively reduced when the active control is applied, in which the time-domain vibration response has been reduced by more than $95 \%$, and the frequency-domain vibration response has been reduced by more than $80 \%$, which means that the vibration reduction effect is obvious.

\section{INTRODUCTION}

The fine-blanking (FB) process as an advanced net shape or near-net shape plastic forming process has been widely applied in industry because of the advantages of high efficiency and high parts quality [1] and [2]. Many mid-thick sheet metal components with complicated shapes and high dimensional accuracy can be fabricated with the FB process in one operation, as shown in Fig. 1a. Compared with the conventional blanking process, a special designed fine-blanking press was required for this process, providing at least three separate forces: blanking force, blank holder force, and counter punch force [3]. Now, almost all FB presses are hydraulic machines with the capacity of $3200 \mathrm{kN}$ to $12000 \mathrm{kN}$ [4], and the forming efficiency is about 30 to 70 times per minute with a punch stroke of $40 \mathrm{~mm}$. With the increasingly huge market demand for the mid-thick sheet metal parts, the FB efficiency should be further improved; the target is about 200 times per minute or higher.

A mechanical servo high-speed FB press was designed and fabricated by our research group and Huangshi Huali Co., Ltd., and the forming efficiency can reach up to 220 times per minute and the maximum forming capacity is $3200 \mathrm{kN}$. The mechanical construction of the main driving system is shown in Fig. 1b, and the main slide block can achieve the trajectory shown in Fig. 1c. With the increasing punch frequency, the vibration of the FB press will become increasingly severe. It is known that the vibration of the press not only affects the parts' quality, such as causing the crack on the cutting surface and reducing the dimensional accuracy but also reducing the service life of the machine. Moreover, the noise caused by the machine vibration will adversely affect working conditions and human health. Therefore, vibration control for the high-speed fine blanking press is urgently required. 


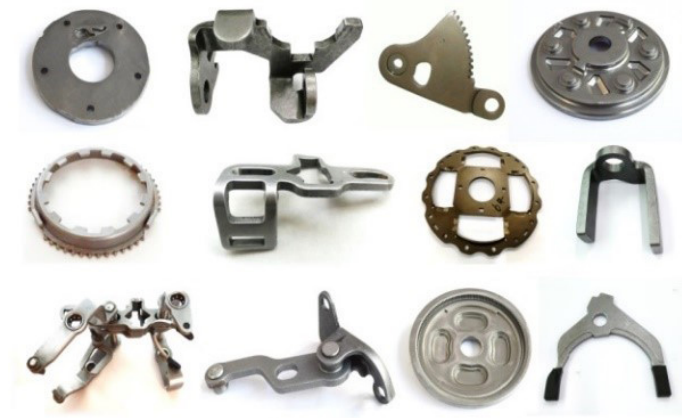

a)
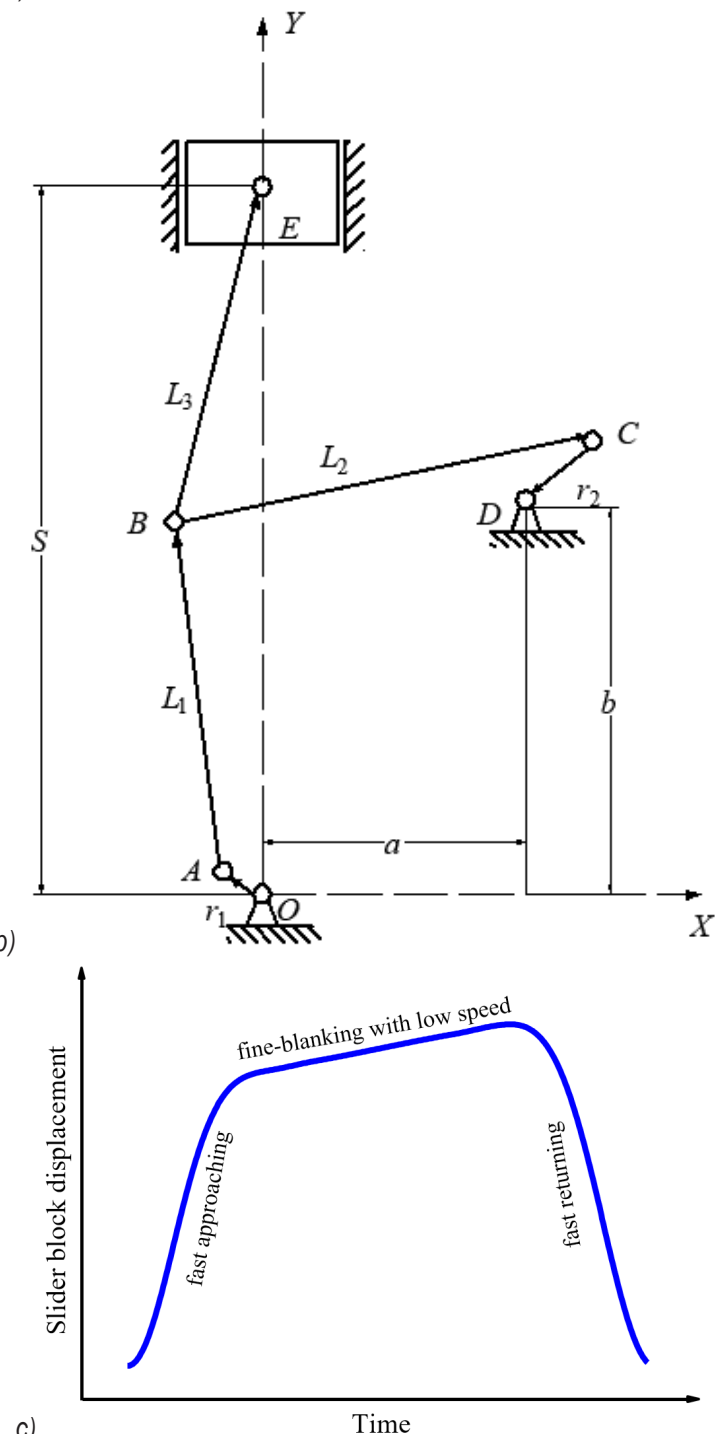

Fig. 1. a) The mid-thick sheet metal parts fabricated by FB process, $b$ ) the mechanical construction of the main driving system of the high-speed FB press, and c) the slide block stroke diagram

In general, the passive control method was applied for the vibration control of the traditional press, such as increasing the stiffness of the frame and adding the vibration isolation system, and the vibration control effort for the excitation source of the press is very rare. For the high-speed FB press proposed in this paper, except for the passive control method, the active vibration control method was also applied to restrain the vibration of the whole machine caused by the elastic restoring force produced by the FB process. Therefore, the low-frequency vibration can be effectively suppressed, so as to reduce the vibration of the mechanical servo high-speed FB press to the greatest extent.

For the research of the active control by Lueg, Guicking [5] submitted, early in 1933, a patent application describing for the first time the principle of active noise cancellation. The basic idea is that using the active control wave with the same amplitude of the noise to counteract the original noise. In 1953, Olson and May [6] invented the electronic sound absorption equipment, which proved the practical feasibility of the active vibration and noise control theory through experiments. Since then, active vibration control technology has been gradually applied to engineering machines. Winberg et al. [7] and Daley et al. [8] applied the active vibration control for the marine applications.

In recent years, many new active vibration control theories have been developed. Shao et al. [9] created the finite element (FE) active vibration control model of the piezoelectric flexible linkage by using the mixed Hamilton principle. Based on the complex mode theory, a hybrid independent mode controller, which consisted of the state feedback and disturbance feed-forward control, was developed. The results showed that the vibration was effectively suppressed for the flexible four-bar linkage. Li [10] studied the active control of submarine vibration system, and a corresponding adaptive control method was put forward. A good control effect of the vibration system by applying the periodic excitation force was obtained. Zhu et al. [11] proposed the active vibration control process for the marine diesel engine, and the $x$-LMS algorithm based on the off-line identification of error channel was used for the active vibration control. Belyi and Gan [12] studied and brought forward a combined bilateral and binaural active noise control algorithm for closed-back headphones. Soni et al. [13] published about the active vibration control of a ship-mounted flexible rotor-shaft-bearing system. Teo and Fleming [14] published optimal integral force feedback for active vibration control in 2015. Park and Kim [15] studied semi-active vibration control of space truss structures by friction damper for the maximization of modal damping ratio in 2013. 
Through the inspiration of the active vibration control method mentioned above, the active vibration control strategy was researched for the mechanical servo high-speed FB press to suppress the periodic low-frequency vibration of the machine. The active vibration control principle of the high-speed FB press was analyzed, and the adaptive vibration controller was created. According to test results of the FB press vibration, the input parameters for the control model were obtained, and the active vibration control effect was predicted by using MATLAB software.

\section{ADAPTIVE VIBRATION CONTROLLER DESIGN}

\subsection{Active Vibration Control System}

The active vibration control system of a mechanical servo FB press is mainly composed of the following parts, as shown in Fig. 2.

(1) Controlled object. In this paper, the controlled object is the mechanical servo FB press. The main drive system of the press is the excitation source of the controlled object; the excitation force acts on the frame and then transfers to the whole machine. Since the elastic restoring force is mainly acted on in the vertical direction, the mathematical model of the controlled object is primarily focused on the vertical deformation.

(2) Measuring mechanics. The core component of the measuring mechanics is the sensor. An acceleration sensor is often used in the data acquisition of vibration response. The vibration signal of the whole machine measured by the acceleration sensor is transmitted to the control system through signal amplification and filtering, which is used as the input parameter of the active vibration control.

(3) Electric actuator. According to the command of the controller, the actuator applies the specified force or torque on the frame of the press and feeds back the action effect to the controller.

(4) Controller. The controller is the core part of the active vibration control system, which can provide the command and control rate of the actuator. Because the main driving system is motorial during the forming process, the adaptive controller which can adjust the parameters of the control system applied in this paper.

(5) Energy and auxiliaries. The external energy supplies the input energy of the actuator for the active vibration control system of the FB press.

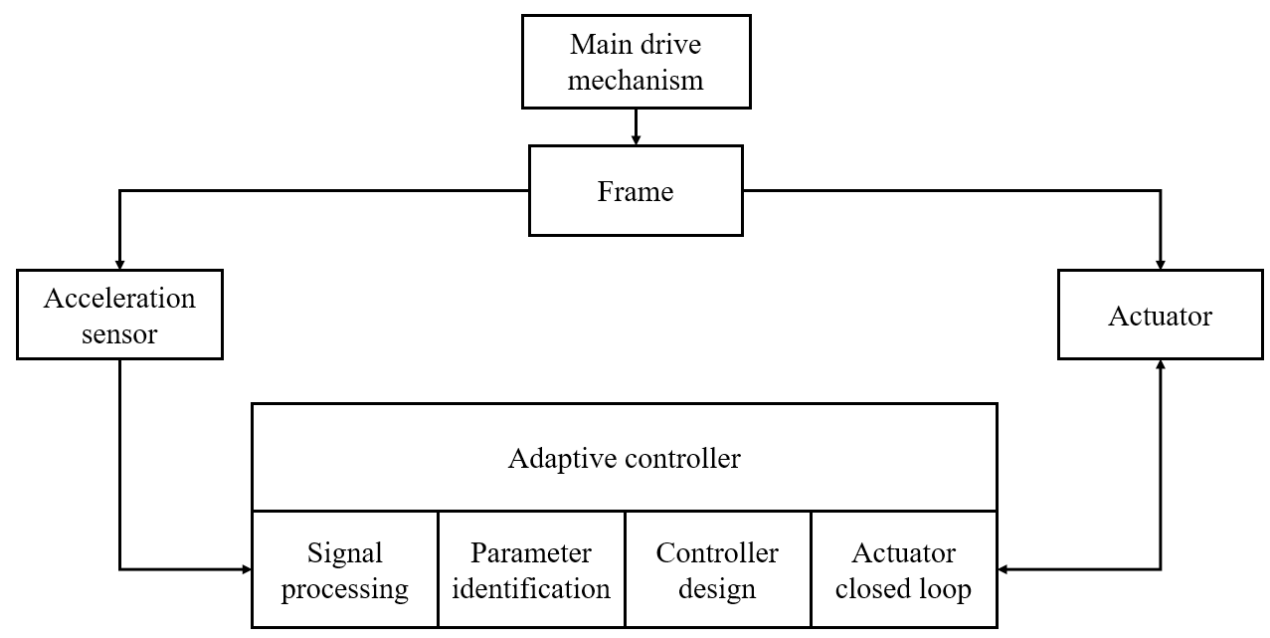

Fig. 2. Schematic diagram of the active vibration control system for FB press

\subsection{Adaptive Vibration Control Algorithm}

The selection and design of the algorithm play an important role in the adaptive vibration controller. Among many adaptive control methods, the least mean square (LMS) adaptive algorithm [16] has been widely used, in which the gradient search method is used, the convergence solution can be obtained quickly, and the implementation is relatively simple.

The LMS algorithm can be expressed by Eq. (1):

$$
\begin{aligned}
F(e(n)) & =\varepsilon(n)=E\left(e^{2}(n)\right) \\
& =E\left[d^{2}(n)-2 d(n) y(n)+y^{2}(n)\right] .
\end{aligned}
$$


The filter of the adaptive active vibration controller adopts the finite impulse response (FIR) structure, and its structure diagram is shown in Fig. 3.

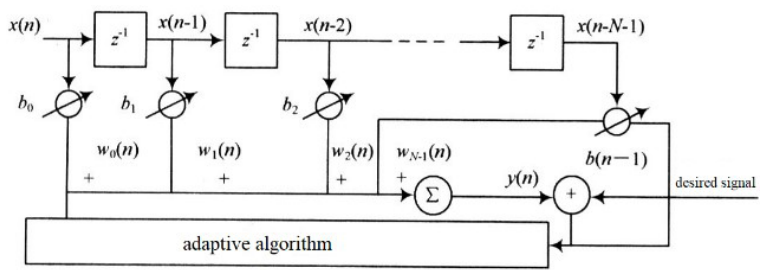

Fig. 3. Adaptive FIR filter

In Fig. $3 x(n)$ represent the input of the adaptive active vibration control filter, $y(n)$ is the output of the adaptive active vibration control filter, $w(n)$ is the impulse response, $w(n)=\{w(0), w(1), \ldots, w(n-1)\}$, then:

$$
y(n)=\mathbf{W}^{\mathrm{T}}(n) \mathbf{X}(n)=\sum_{i=0}^{N-1} w_{i}(n) x(n-i)
$$

For the filter with transverse structure, substitute the expression of into Eq. (1):

$$
\varepsilon=E\left(\mathbf{d}^{2}(n)\right)+\mathbf{W}^{\mathrm{T}}(n) \mathbf{R W}(n)-2 \mathbf{W}^{\mathrm{T}}(n) \mathbf{P},
$$

where where $\mathbf{R}=E\left[\mathbf{X}(n) \mathbf{X}^{\mathrm{T}}(n)\right]$ is the autocorrelation matrix of $\mathbf{N} \times \mathbf{N}$, is the cross-correlation vector for $\mathbf{N} \times 1$, which represents the correlation between the ideal signal $\mathbf{d}(n)$ and the input vector.

Because the gradient descent method is adopted for the optimization process, so:

$$
\frac{\partial \varepsilon}{\partial \mathbf{W}(n)_{w(n)=w^{*}}}=0
$$

When the mean square error reaches to the minimum value, the optimal weight coefficient can be obtained.

If the $\mathbf{R}$ matrix is full rank, the best value of the weight coefficient should be satisfied with $\mathbf{W}^{*}=\mathbf{R}^{-1} \mathbf{P}$, namely:

$\left[\begin{array}{c}w_{0}^{*} \\ w_{1}^{*} \\ \vdots \\ w_{(n-1)}^{*}\end{array}\right]=\left[\begin{array}{cccc}\phi_{x}(0) & \phi_{x}(1) & \cdots & \phi_{x}(n-1) \\ \phi_{x}(1) & \phi_{x}(0) & \cdots & \phi_{x}(n-2) \\ \vdots & \vdots & \ddots & \vdots \\ \phi_{x}(n-1) & \phi_{x}(n-2) & \cdots & \phi_{x}(0)\end{array}\right]^{-1}\left[\begin{array}{c}\phi_{x d}(0) \\ \phi_{x d}(1) \\ \vdots \\ \phi_{x d}(n-1)\end{array}\right]$,

where, $\quad \phi_{x}(m)=E[x(n) x(n-m)] \quad$ shows the autocorrelation value of $x(n), \phi_{x d}(k)=E[x(n) d(n-k)]$ represents the cross-correlation value between $x(n)$ and $d(n)$.

In practical applications, it is difficult to obtain the autocorrelation and cross-correlation values of signals. Therefore, gradient estimation value can be used, that is:

$$
\begin{aligned}
\hat{g}_{w}(n) & =-2 d(n) x(n)+2 x(n) x^{\mathrm{T}}(n) w(n) \\
& =2 x(n)\left(-d(n)+x^{\mathrm{T}}(n) w(n)\right) .
\end{aligned}
$$

Using the gradient estimation value to replace the real values, then:

$$
w(n+1)=w(n)+2 \mu e(n) x(n) .
$$

This is the iterative equation of the LMS algorithm. In practical application, the step size is fixed, and the value of will affect the performance of the algorithm, resulting in the change of convergence speed, jump tracking ability and steady-state imbalance of the algorithm. Since the most appropriate value is very difficult to obtain, the variable step size normalized LMS algorithm is usually applied, which can be expressed as:

$$
w(n+1)=w(n)+2 \mu_{n} e(n) x(n)=w(n)+\Delta w(n) .
$$

According to the expression of the instantaneous square error of the LMS algorithm, the instantaneous square error of variable step size normalized LMS algorithm can be expressed as:

$$
\begin{aligned}
\tilde{e}^{2}(n) & =e^{2}(n)+2 \Delta w^{\mathrm{T}}(n) x(n) x^{\mathrm{T}}(n) w(n) \\
& +\Delta w^{\mathrm{T}}(n) x(n) x^{\mathrm{T}}(n) w(n)-2 d(n) \Delta w^{\mathrm{T}}(n) x(n),(9)
\end{aligned}
$$

then:

$$
\begin{aligned}
\Delta e^{2}(n) & =\tilde{e}^{2}(n)-e^{2}(n)= \\
& -2 \Delta w^{\mathrm{T}}(n) x(n) e(n) \\
& +\Delta w^{\mathrm{T}}(n) x(n) x^{\mathrm{T}}(n) w(n) .
\end{aligned}
$$

From $\Delta w(n)=2 \mu_{n} e(n) x(n)$, we can get:

$$
\begin{aligned}
\Delta e^{2}(n) & =-4 \mu_{n} e^{2}(n) x^{\mathrm{T}}(n) x(n) \\
& +4 \mu_{n} e^{2}(n)\left[x^{\mathrm{T}}(n) x(n)\right]^{2} .
\end{aligned}
$$

To minimize $\Delta e^{2}(n)$, which makes the instantaneous square error close to the square error, we can take $d \Delta e^{2}(n) / d \mu_{n}=0$, then,

$$
\mu_{n}=\frac{1}{2 x^{\mathrm{T}}(n) x(n)} .
$$

In order to avoid the steady-state imbalance, a fixed numerical convergence factor $\mu_{k}$ is introduced to avoid a large step size when the denominator is very small during the iteration process. At the same time, another parameter $\gamma$ is introduced to adjust the denominator. Then the updated iterative equation of the new variable step size normalized LMS algorithm is: 


$$
w(n+1)=w(n)+\frac{\mu_{k}}{\gamma+x^{\mathrm{T}}(n) x(n)} e(n) x(n) .
$$

\subsection{Adaptive Feedforward Active Vibration Control of the Fine-Blanking Press}

As mentioned in Section 1.1, the main drive system of the press applies vertical excitation force to the whole machine, including the frame. The actuator is installed on the frame, which can exert a controllable force with the opposite direction of the excitation force of the main drive system to offset the original vibration and realize active vibration reduction.

Because the vibration on the frame is easy to measure, the upper and lower cross-beams of the frame are selected as the vibration observation parts of the control system. The excitation force generated by the main drive system is transmitted to the frame through the primary channel to generate the vibration response, which can be used as the reference input of the adaptive active vibration control. is the control input, and the value is the estimated value of the excitation force. By adjusting the with the adaptive feed-forward control method, the vibration response of the frame can be reduced, and the effect of reducing the vibration of the whole machine can be achieved. The control block diagram is shown in Fig. 4.

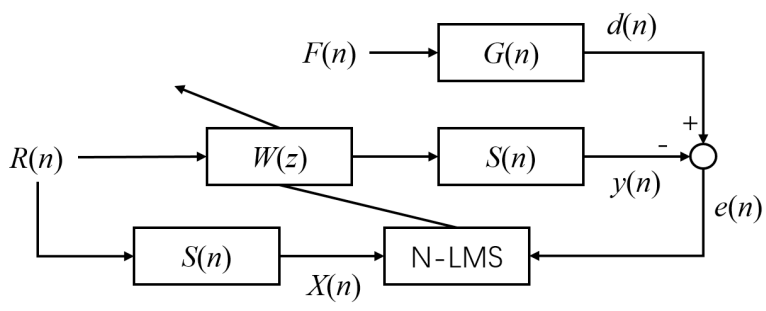

Fig. 4. Active vibration control block diagram of the FB press

In Fig. 4, $F(n)$ is the excitation force generated by the main drive system, $d(n)$ is the excitation force response used as the reference input, $e(n)$ is the control system error and also used as the controlled output when the control system is stable, $W(z)$ is the adaptive controller, $R(n)$ is the estimated value of the excitation force, $G(n)$ is the transfer function which reflects the excitation force transferred to the frame, $S(n)$ is the transfer function which reflects the control force transferred to the frame. The FIR filter described above is adopted as the filter.

Based on the above control block diagram, the mean square error of the whole control system can be expressed as Eq. (1).
Then the control output $y(n)$ of the $n^{\text {th }}$ order filter is equal to the convolution operation:

$$
\begin{aligned}
y(n) & =S(n) \times \sum_{i}^{N} w(n) R(n) \\
& =\int_{0}^{\infty} S(n-\tau) \times\left(\sum_{i}^{N} w(\tau) R(\tau)\right),
\end{aligned}
$$

then the gradient value of the mean square error can be calculated as:

$$
g_{w}=\frac{d E\left[e^{2}(n)\right]}{d w}=-E[2 e(n) S(n) R(n)] .
$$

According to the variable step-size normalized LMS algorithm, the variable step-size factor $\mu$ needs to be transformed, that is:

$$
\mu=\frac{1}{2(S(n) R(n))^{\mathrm{T}}(S(n) R(n))},
$$

then the iterative equation of the weight updating of the adaptive control algorithm can be obtained:

$$
w(n+1)=w(n)+\frac{\mu_{n}}{\gamma+x^{\mathrm{T}}(n) x(n)} e(n) x(n),
$$

where, $X(n)=S(n) R(n)$.

\section{VIBRATION MECHANICAL MODEL DESIGN}

\subsection{Vibration Mechanical Model of the Fine Blanking Press}

For the adaptive active vibration control system of the fine blanking machine, establishing the mechanical vibration model of the controlled object and obtaining the transfer function of the control system are required. It is assumed that the material distribution before each blanking process can be restored, and the material penetration is not considered. The punching force is located in the vertical direction, so the vertical direction, which has the maximum deformation, is mainly considered. Therefore, the structure of the FB press can be expressed as a combination of linear spring dampers.

Then the mechanical vibration model as shown in Fig. 5 can be established, and the motion equation for each mass block can be expressed as follows.

$$
m_{i} \ddot{x}_{i}=\sum F_{i}^{i m p}+\sum F_{i}^{e l},
$$

where $F_{i}^{i m p}$ is the sum of the impact forces exerted on the mass $m_{i}, F_{i}^{e l}$ is the sum of the elastic forces applied to the mass $m_{i}$.

The excitation source of the whole press comes from the main drive system. The excitation force 
acting on the main drive system is mainly composed of two parts. One part is the unbalanced inertia force $F_{y}$, generated by the main drive system itself. The other part mainly is the elastic restoring force from the main drive system at the ending of the FB process, which is relatively difficult to obtain; this can be done so with the FE simulation of the FB process. The FB FE model is shown in Fig. 5. The material for this simulation is TC4 titanium alloy with a thickness of 5 $\mathrm{mm}$. The diameter of the fine-blanked part is $20 \mathrm{~mm}$, and the $\mathrm{FB}$ speed is $5 \mathrm{~mm} / \mathrm{s}$. The relationship between the FB force and the time can be obtained, as shown in Fig. 6. When the punch force acts on the workpiece, the reaction force exerts on the main drive system in the opposite direction, which reflects the changing of the impact load acting on the main drive system.

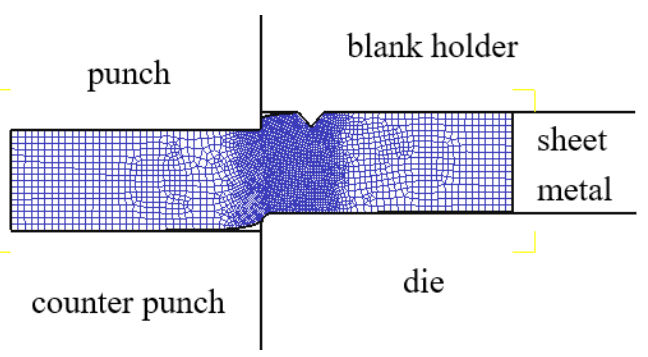

Fig. 5. The FE model of the FB process

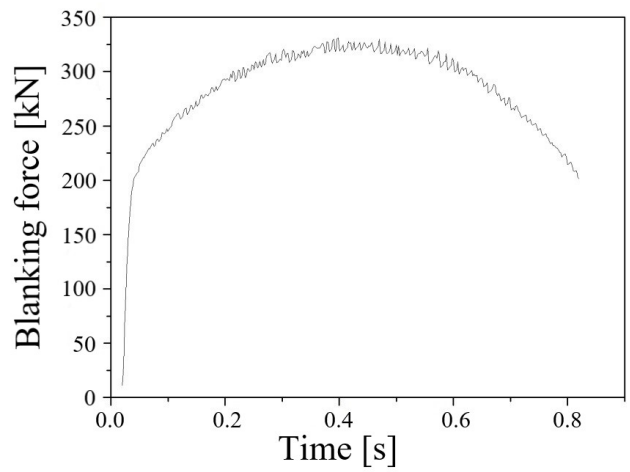

Fig. 6. The relationship between the fine-blanking force and the time

According to the mechanical vibration model, as shown in Fig. 7, the vibration equations of each mass block can be expressed by:

$$
\left\{\begin{array}{c}
m_{7} \ddot{x}_{7}+c_{7}\left(\dot{x}_{7}-\dot{x}_{8}\right) \\
+k_{7}\left(x_{7}-x_{8}\right)=F^{i m p}+F_{y} \\
m_{8} \ddot{x}_{8}+c_{8}\left(\dot{x}_{8}-\dot{x}_{9}\right)+c_{7}\left(\dot{x}_{8}-\dot{x}_{7}\right) \\
+k_{8}\left(x_{8}-x_{9}\right)+k_{7}\left(x_{8}-x_{7}\right)=0 \\
m_{9} \ddot{x}_{9}+c_{9} \dot{x}_{9}+c_{8}\left(\dot{x}_{9}-\dot{x}_{8}\right) \\
+k_{9} x_{9}+k_{8}\left(x_{9}-x_{8}\right)=0
\end{array}\right.
$$

where $m_{7}, k_{7}, c_{7}$, and $x_{7}$ represent the mass, equivalent stiffness, equivalent damping and displacement of the main drive, respectively. $m_{8}, k_{8}, c_{8}$, and $x_{8}$ represent the mass, equivalent stiffness, equivalent damping and displacement of the frame, respectively. $m_{9}, k_{9}, c_{9}$, and $x_{9}$ represent the mass, equivalent stiffness, equivalent damping and displacement of the embedded footings, respectively. $k_{10}$ and $c_{10}$ represent the equivalent stiffness and damping of the upper worktable. $\ddot{x}_{j}$ and $\dot{x}_{j}(j=6,7,8)$ represent the acceleration and velocity of the mass block.

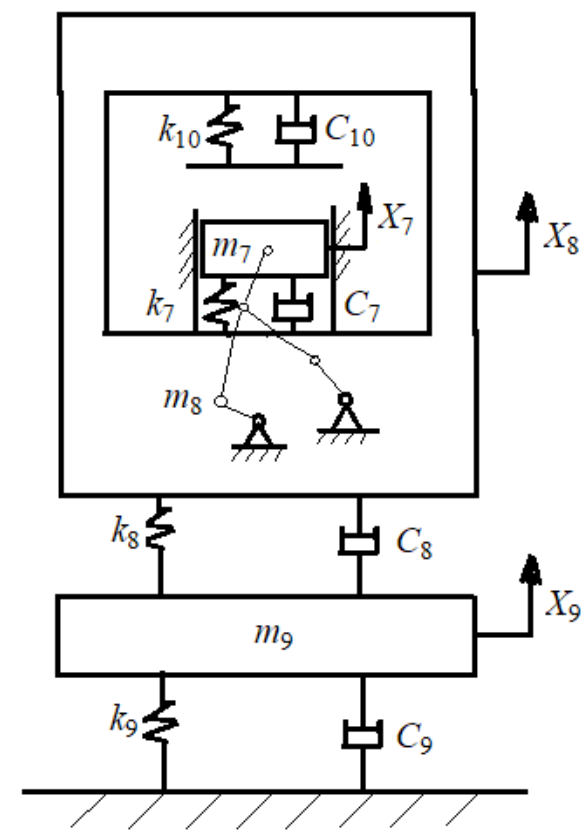

Fig. 7. Vibration mechanical model of the FB press

\subsection{Parameters Determination of the Vibration Mechanical Equation}

In order to solve the mechanical vibration equation, the parameters, such as the equivalent mass, equivalent stiffness, equivalent damping value and similar parameters, should be determined firstly based on the FB press structure.

\subsubsection{Embedded Footings System}

Fig. 8 shows the foundation installation system for the FB press. For the embedded foundation in the deep homogeneous layer, we can use the formulas presented in [17] and [18] to calculate the stiffness and damping value. That is: 


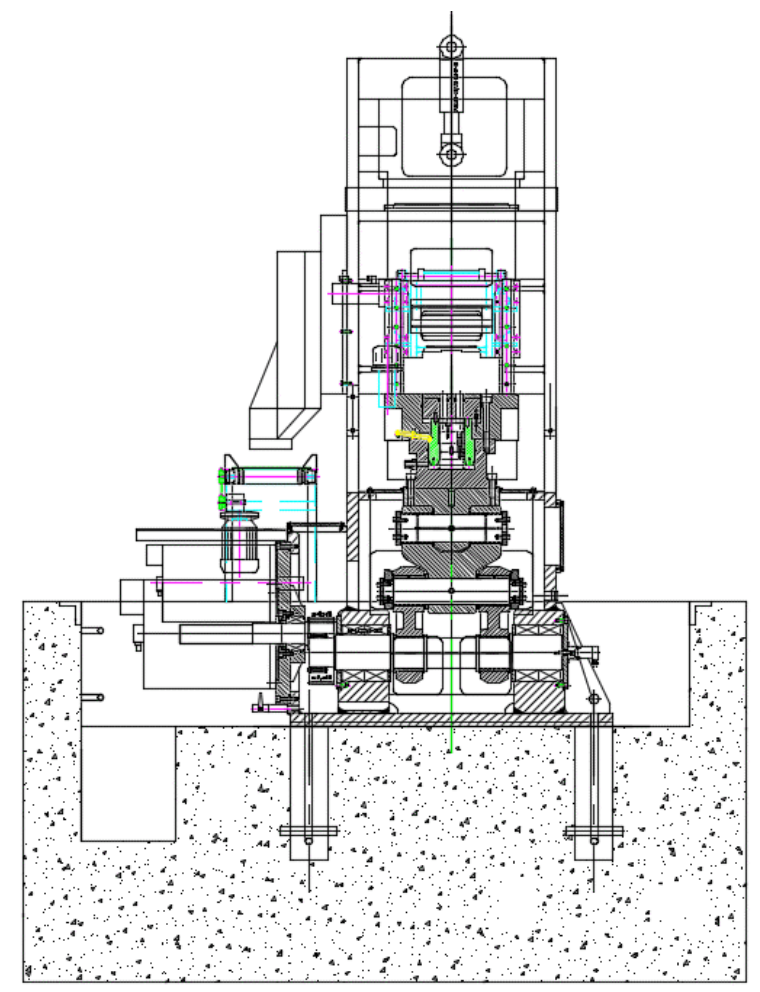

Fig. 8. Foundation installation design of mechanical fine blanking machine

$$
\left\{\begin{array}{c}
k=G r_{0}\left(C_{v 1}+\frac{G_{S}}{G} \frac{l}{r_{0}} S_{v 1}\right) \\
c=r_{0}^{2} \sqrt{\rho G}\left(\bar{C}_{v 2}+\bar{S}_{v 2} \frac{l}{r_{0}} \sqrt{\frac{\rho_{S}}{\rho} \frac{G_{S}}{G}}\right)
\end{array}\right.
$$

where $G$ is the shear modulus of the soil, $r_{0}$ is the radius of circular foundation or the equivalent radius of non-circular foundation. $\rho$ is the density of the soil, $l$ is the depth of embedment, $G_{S}$ and $\rho_{S}$ are the shear modulus and density of the backfill side layer, respectively. Dimensionless stiffness and damping parameters $C_{v 1}$ and $\bar{C}_{\underline{v} 2}$ depend on the dimensionless frequency. $\quad S_{v 1}$ and $\bar{S}_{v 2}$ are the dimensionless stiffness and damping parameter of the side layer. Novak [19] provided the $C_{v 1}, \bar{C}_{v 2}, S_{v 1}$ and $\bar{S}_{v 2}$ for most stamping equipment, as shown in Table 1.

Table 1. Reference values of stiffness and damping for foundation installation system

\begin{tabular}{lcccc}
\hline \multirow{2}{*}{ soil } & \multicolumn{2}{c}{ Half-space } & \multicolumn{2}{c}{ Side layer } \\
\cline { 2 - 5 } & $C_{v 1}$ & $\bar{C}_{v 2}$ & $S_{v 1}$ & $\bar{S}_{v 2}$ \\
\hline Cohesive soil & 7.5 & 6.8 & 2.7 & 6.7 \\
\hline Granular soil & 5.2 & 5.0 & & \\
\hline
\end{tabular}

Based on the installation conditions of the mechanical servo FB press, the average shear wave velocity of soil is $150 \mathrm{~m} / \mathrm{s}$, and the density is 1900 $\mathrm{kg} / \mathrm{m}^{3}$. The total mass of the foundation system is taken as $400,000 \mathrm{~kg}$. The average shear wave velocity of backfill material is $120 \mathrm{~m} / \mathrm{s}$, and the mass density is $2400 \mathrm{~kg} / \mathrm{m}^{3}$. The shear modulus of soil can be evaluated by $G=\rho V_{S}^{2}$, and it is $42.75 \mathrm{MPa}$ for footing and $25.9 \mathrm{MPa}$ for the side layer. Therefore, the stiffness and damping constants of the foundation installation system can be calculated by Eq. (21), which is $k=8.1 \times 10^{8} \mathrm{~N} / \mathrm{m}$ and $c=1.1 \times 10^{7}(\mathrm{~N} / \mathrm{m}) / \mathrm{s}$.

\subsubsection{Frame Part}

Because of the complexity of the frame structure, the FE method is usually used to obtain the equivalent stiffness of the frame mass. As shown in Fig. 9, the bottom surface is fixed by four points, and the upper cross-beam is applied with $200 \mathrm{~N}$ uniform force to get the deformation of the frame. According to the simulation results, the maximum deformation of the frame is $6.7324 \times 10^{-8} \mathrm{~m}$. Therefore, the equivalent stiffness of the frame can be calculated with:

$$
\begin{aligned}
k_{f} & =\frac{F_{f}}{\Delta l}=\frac{200}{6.7324 \times 10^{-8}}[\mathrm{~N} / \mathrm{m}] \\
& =2.971 \times 10^{9}[\mathrm{~N} / \mathrm{m}] .
\end{aligned}
$$

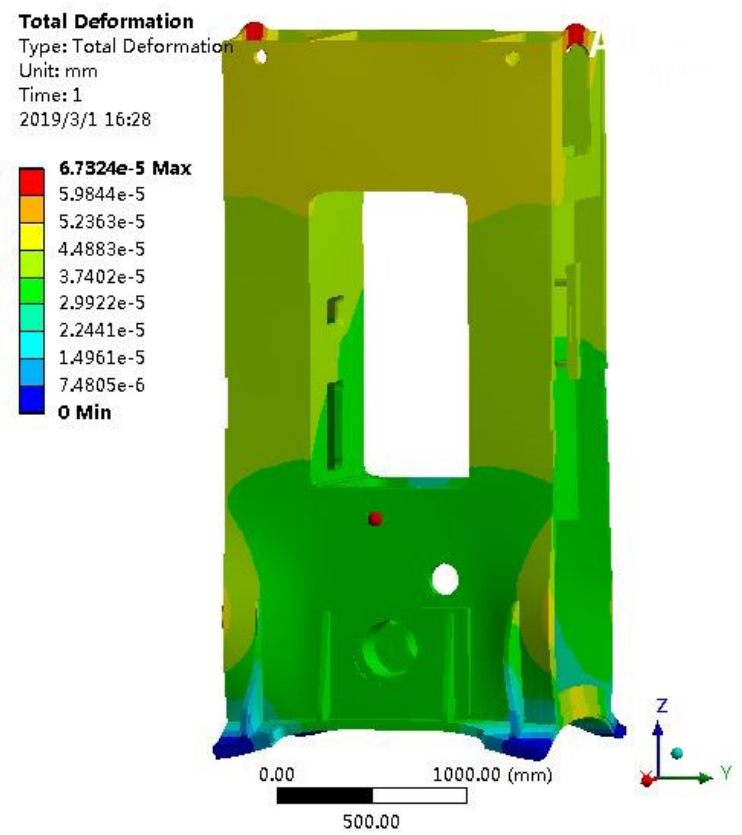

Fig. 9. Frame deformation under the action of the constant load 
It is somewhat difficult to calculate the equivalent damping value of the frame. In general, it is required to calculate the logarithmic decrement rate $\delta$ of the system response under the impact vibration. The relationship between the logarithmic decrement rate and the structural damping ratio is shown in Eq. (22):

$$
\delta=\operatorname{In} \frac{x_{i}}{x_{i+T}}=\frac{2 \pi \xi}{\sqrt{1-\xi^{2}}},
$$

where $\xi$ is the damping ratio of the frame, $x_{i}$ is the displacement, velocity or acceleration amplitude on the frame at the time of $t_{i}, x_{i+T}$ is the displacement, velocity or acceleration amplitude on the same location at the time of $t_{i+T}$.

Because the value of $\xi$ is very small, it can be ignored after the square. Then, Eq. (22) can be simplified as:

$$
\delta=\operatorname{In} \frac{x_{i}}{x_{i+t}}=2 n \pi \xi
$$

Based on Eq. (23), once the logarithmic decrement rate $\delta$ is determined, the damping ratio $\xi$ of the frame can be obtained.

$$
c=2 \xi \sqrt{m k} \text {. }
$$

Therefore, to obtain the equivalent damping of the frame, the logarithmic decrement rate of the vibration amplitude of the system under the impact load should be calculated first. Based on the above FE model, $1 \mathrm{MN}$ impact force is applied to the frame workbench and the bearing seat hole with a time of $0.02 \mathrm{~s}$. According to the simulation result, the maximum acceleration and velocity changing point on the frame can be obtained, as shown in Fig. 10.

Based on the plots in Fig. 10, the following equivalent damping parameters can be obtained and summarized in Table 2.

Table 2. Equivalent damping parameters of the frame

\begin{tabular}{lcccc}
\hline & \multicolumn{2}{c}{ Value } & $\begin{array}{c}\text { Logarithmic } \\
\text { decrement rate }\end{array}$ & $\begin{array}{c}\text { Damping ratio } \\
\text { of frame }\end{array}$ \\
\cline { 2 - 5 } & $t_{i}$ & $t_{i+T}$ & $\delta$ & $\xi$ \\
\hline Velocity $v_{7}$ & 0.272 & 0.103 & 0.971 & 0.154 \\
\hline Acceleration $a_{7}$ & 6.691 & 2.731 & 0.896 & 0.143 \\
\hline
\end{tabular}

Based on the numbers in Table 2, it can be seen that the damping ratio of the frame is near 0.15 . Therefore, it can be taken as 0.15 . It is also known that the total mass of the frame is $12,314 \mathrm{~kg}$. According to Eqs. (22) to (24), the equivalent damping value of the frame can be obtained as $c_{7}=1.81 \times 10^{6}$.
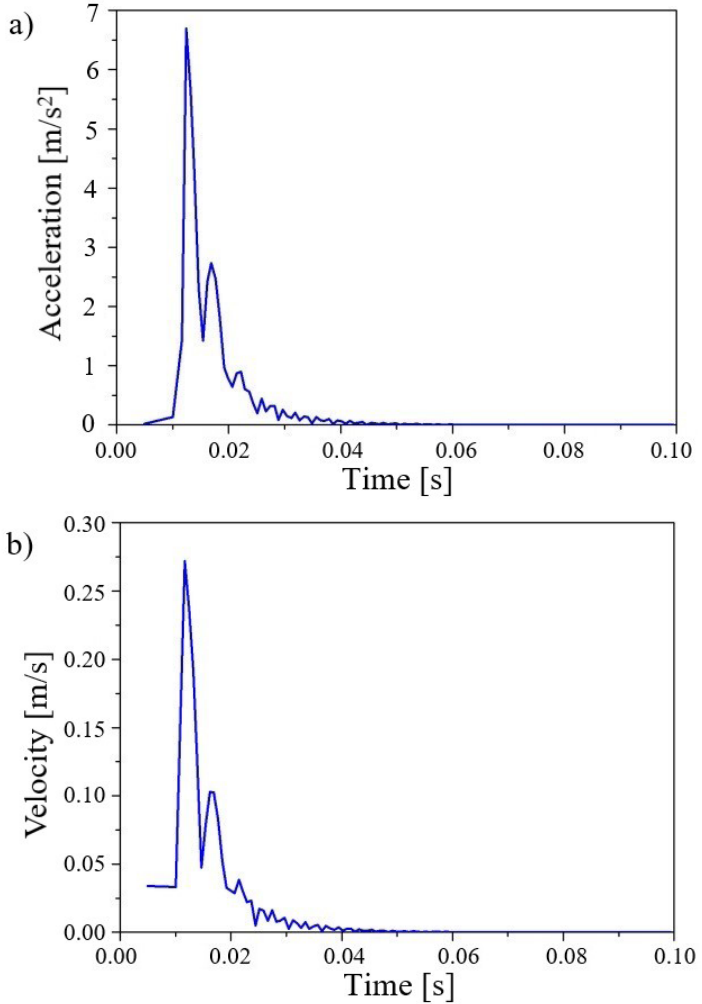

Fig. 10. Acceleration and velocity attenuation on the frame under the impact load; a) acceleration, and b) velocity

\subsubsection{Main Drive System}

For the main drive system, the equivalent stiffness and damping can be obtained with the same method applied for the frame part. The FE model for the main drive system was created as shown in Fig. 11, in which the support constraint is applied to the bearing pedestal at the bottom of the main drive system, and the horizontal displacement of the slide block is constrained. The deformation of the main drive system can be obtained by applying $200 \mathrm{~N}$ uniform force load on the top of the slider, as shown in Fig. 11.

Based on the plots in Fig. 10 that the maximum deformation of the main drive system under the constant load is $6.0265 \times 10^{-7}$. Then, the equivalent rigidity of the main drive system can be obtained by Eq. (25):

$$
k_{T}=\frac{F_{T}}{\Delta l}=\frac{200}{6.0265 \times 10^{-7}}=3.32 \times 10^{8}[\mathrm{~N} / \mathrm{m}] .
$$

In order to obtain the equivalent damping of the main drive system, the $10^{5} \mathrm{~N}$ impact is applied to the top surface of the slider for $0.02 \mathrm{~s}$. The maximum acceleration and velocity changing point on the main 
drive system can be obtained from the simulation results as shown in Fig. 12.

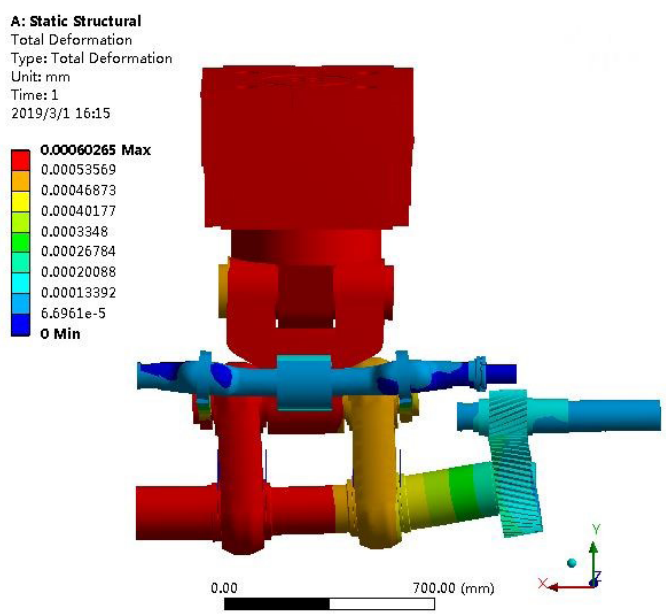

Fig. 11. Deformation of the main drive system under the constant load

a)

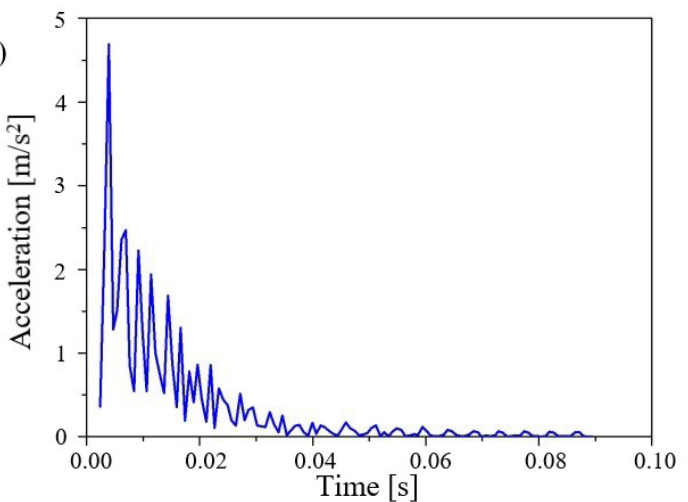

b)

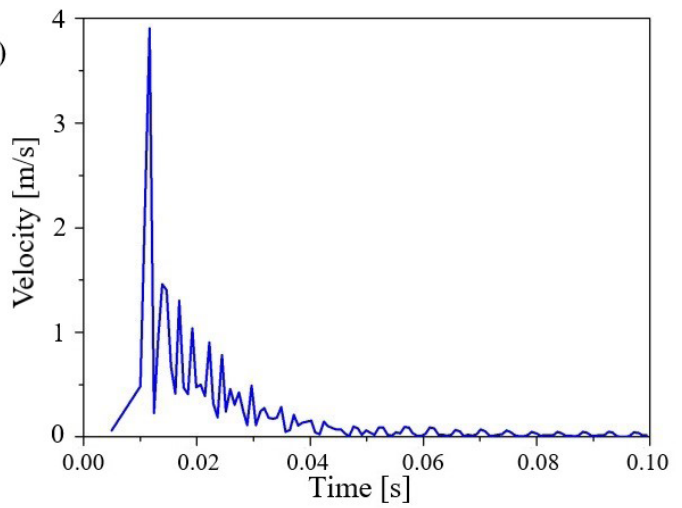

Fig. 12. Acceleration and velocity attenuation of the main drive system under the impact load; a) acceleration, and b) velocity

Based on the plots in Fig. 12, the following equivalent damping parameters can be obtained and summarized in Table 3.
Table 3. Equivalent damping parameters of the main drive system

\begin{tabular}{lcccc}
\hline & \multicolumn{2}{c}{ Value } & $\begin{array}{c}\text { Logarithmic } \\
\text { decrement rate }\end{array}$ & $\begin{array}{c}\text { Damping ratio } \\
\text { of frame }\end{array}$ \\
\cline { 2 - 5 } & $t_{i}$ & $t_{i+T}$ & $\delta$ & $\xi$ \\
\hline Velocity $v_{6}$ & 1.601 & 1.038 & 0.433 & 0.069 \\
\hline Acceleration $a_{6}$ & 4.689 & 2.773 & 0.436 & 0.069 \\
\hline
\end{tabular}

According to the parameters obtained in Table 3 , the value of the damping ratio of the main drive system is approximately 0.069 . It is also known that the total mass of the main drive system is $2,592 \mathrm{~kg}$. According to Eqs. (23) to (25), the equivalent damping value of the main drive system can be obtained as $c_{6}=1.28 \times 10^{5}$.

After obtaining the parameters of each part, the mechanical vibration model of the controlled object can be finally established and used in the active vibration control simulation.

\section{NUMERICAL SIMULATION AND DISCUSSION}

\subsection{Analog Excitation Input}

Because the effect of the vertical excitation force on the forming accuracy is the most direct and the largest, the reference excitation force input of the active vibration control can be composed of the blanking force excitation during the FB process and the unbalanced inertia force excitation during the nonworking process. In order to simulate the error during the active vibration control process, the random vibration interference is added to the reference excitation input, which is shown in Fig. 13.

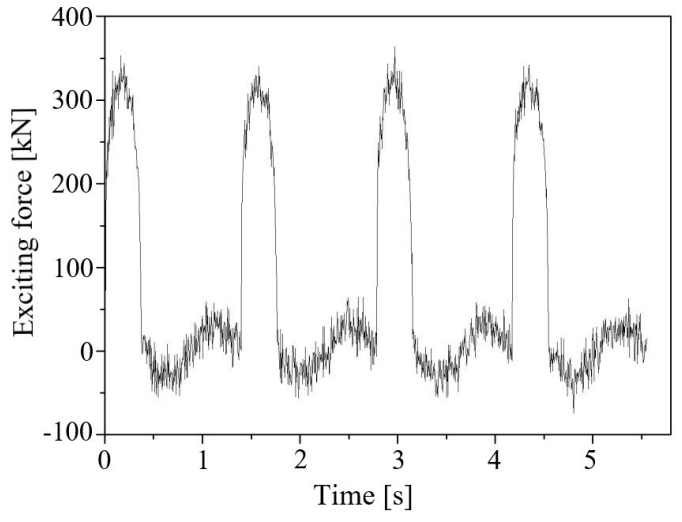

Fig. 13. Reference excitation force input 


\subsection{Reference Input Based on the Measured Vibration Response}

\subsubsection{Vibration Measurement Scheme of Fine-Blanking Machine}

The composition of the vibration measurement system of the mechanical servo FB press can be depicted by the schematic diagram shown in Fig. 14. During the working process, the vibration at the working area is the most obvious, which has a direct impact on the forming accuracy. Therefore, the vibration in the working area needs to be measured. Meanwhile, the rigidity of the frame in the middle area is much smaller than that of the upper and lower cross-beams, and the guide rail of the slide block is arranged on the frame column in the middle area. Therefore, measuring points need to be arranged on the inner side of the stand column to reflect the vibration mode of the whole machine. Consequently, the measuring points arranged at the worktable area of the FB press are shown in Fig. 15, and 12 three-way acceleration sensors are even distributed at the working area.

\subsubsection{Test Results of Measuring Points}

During the test, the mechanical servo FB press works periodically with a speed of 87 times per minute under

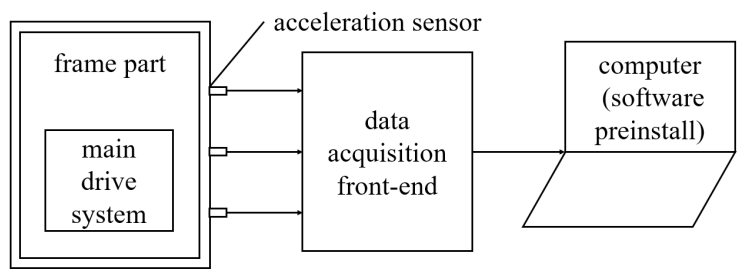

Fig. 14. Vibration measurement schematic diagram

the no-load condition. In the movement process, the inertial load affects the lower cross-beam directly, and the vibration will be transmitted to the worktable, resulting in the forming error. The bottom of the lower cross-beam connected with the ground by installation system, the overall stiffness is very large. Therefore, the acceleration response of measuring points 1,2 , and 3 can reflect the overall response of the lower cross-beam, which is shown in Fig. 16.

Compared with the upper and lower cross-beams, the rigidity of the frame columns on the left and right sides in the middle is smaller, and the deformation will have a great impact on the whole press deformation. As the left and right columns are of symmetrical structure, the deformation situation is similar from the results, so the deformation situation on the right side is selected for the analysis. The response situations in time domain and frequency domain are shown in Fig. 17.
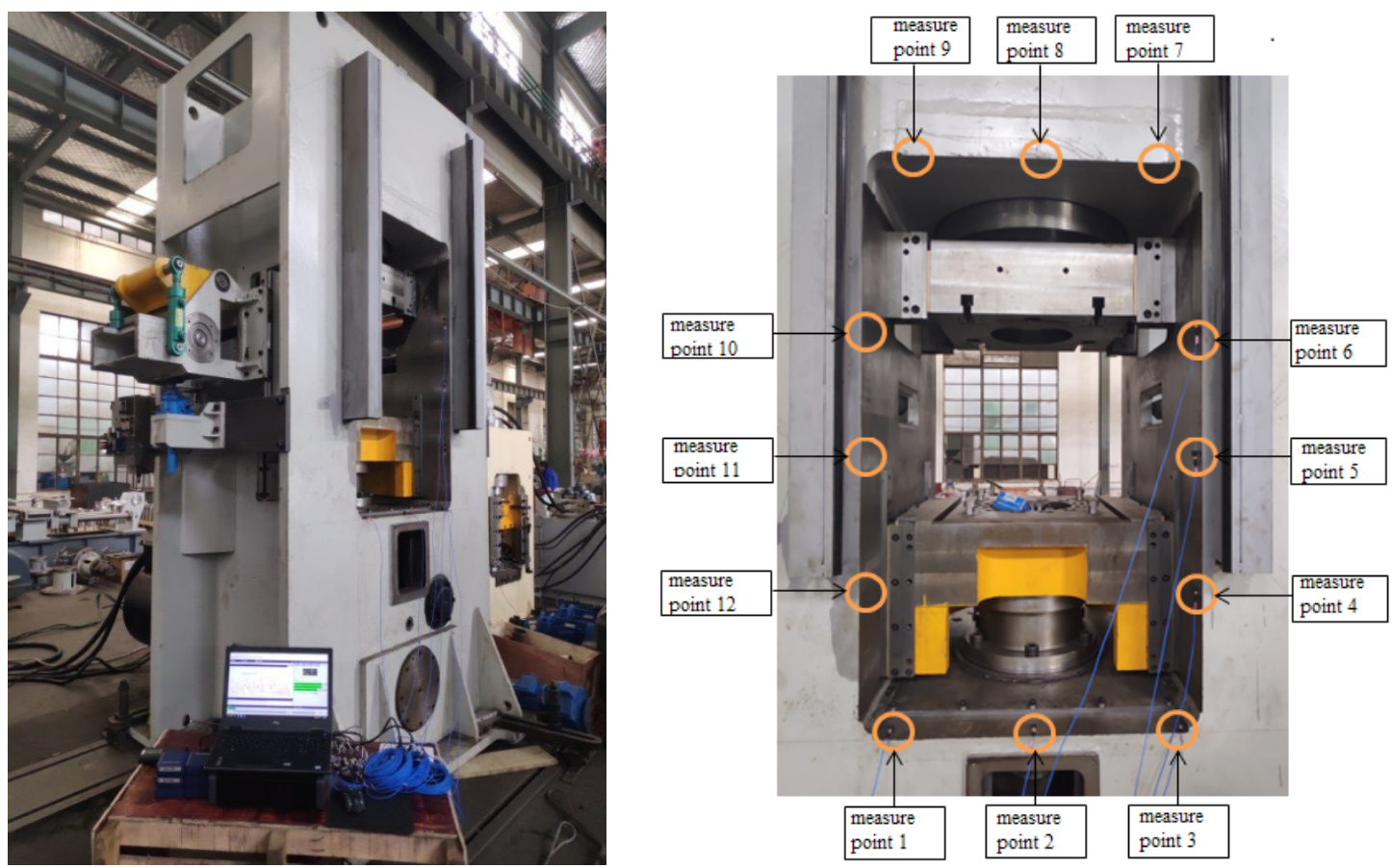

Fig. 15. Measuring points distribution at the working area 
Based on the plots in Figs. 16 and 17, when the frequency is about $200 \mathrm{~Hz}$, points of 4, 5 and 6 have a stronger frequency response than the points of 1,2 and 3 .

The overall rigidity of the upper cross-beam is very large. Because the upper cross-beam is far from the frame installation system, it is easy to produce large vibration response. The response situations in the time and frequency domain are shown in Fig. 18.

Based on the plots in Figs. 16 to 18, points of 7, 8 and 9 have a stronger frequency response when the frequency is about $150 \mathrm{~Hz}$ than points of $1,2,3,4,5$ and 6 . But have a weaker frequency response when the frequency is about $200 \mathrm{~Hz}$.

\subsection{Numerical Simulation Results}

According to the self-adaptive vibration feed-forward control method, as described in Section 2, the control system simulation process is programmed in the
MATLAB software platform, and the value of $\mu_{k}$ is $0.005, \gamma$ is $10^{-5}$. Combined with the mechanical model of the controlled object, the time-domain vibration response of each observation point with and without control can be obtained, as shown in Fig. 19a. The simulation results show that the control effect of all measuring points is very good, so we use measuring point 2 to show. The frequency domain vibration response of observation point 2 with and without control can be obtained, as shown in Fig. 19b.

In Fig. 19, the blue line represents the vibration response output without control, and the red line represents the vibration response output adding active control. It can be seen from Fig. 19 that the vibration response of the press with the active vibration control is effectively reduced. The time-domain vibration response quickly achieves stability when the active control applied and the convergence speed is very fast, which means that it has a stable control effect at that time. It can be seen that the vibration of the frame
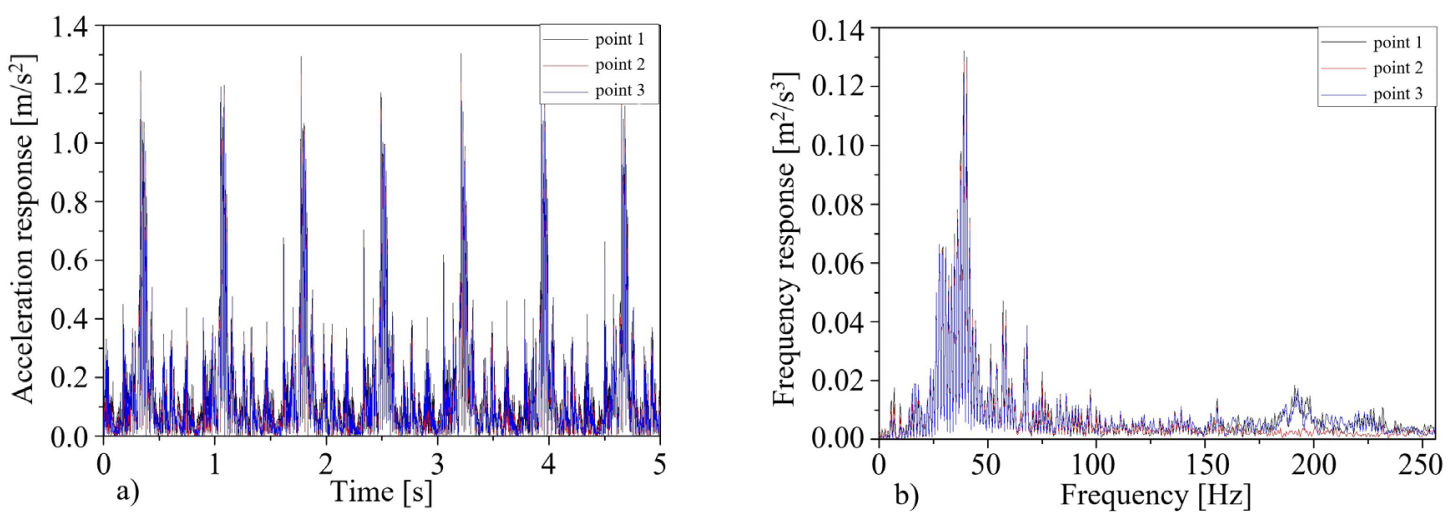

Fig. 16. Response of Z-direction time domain and frequency domain of measuring points at the lower cross-beam area (measuring points of 1,2 and 3); a) time domain response diagram, and b) frequency domain response diagram
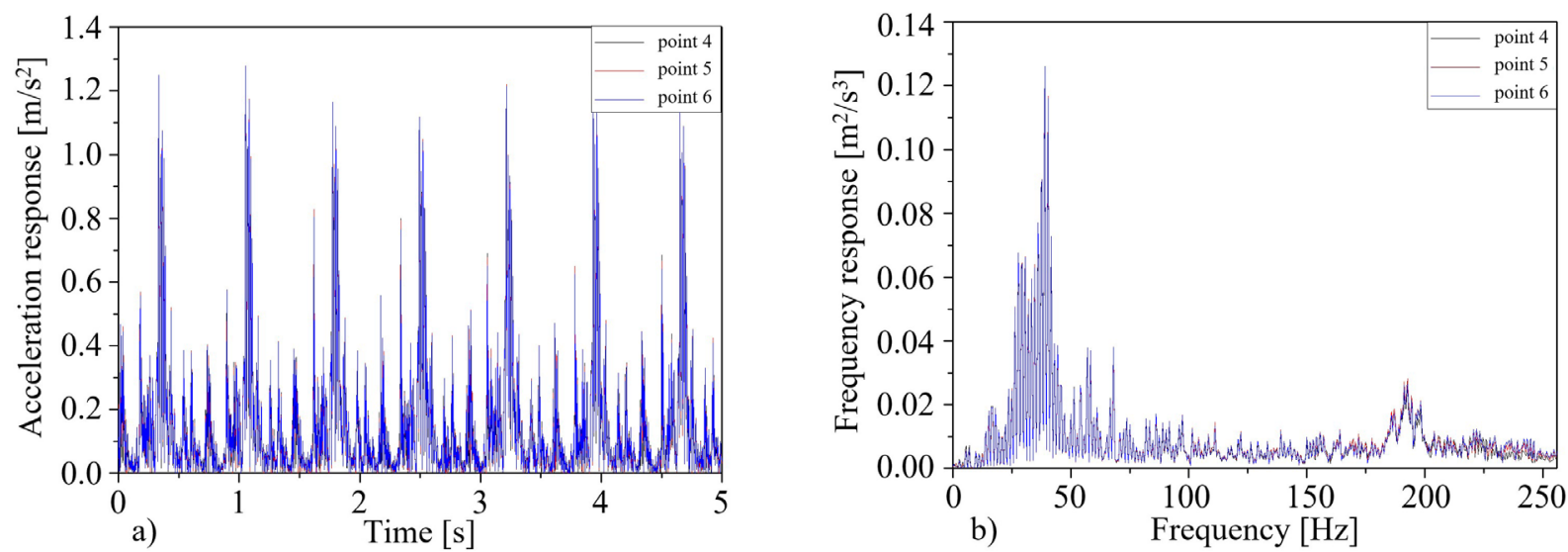

Fig. 17. Response of Z-direction time domain and frequency domain of measuring point at frame column area (measuring points of 4, 5 and 6); a) time domain response diagram, and b) frequency domain response diagram 

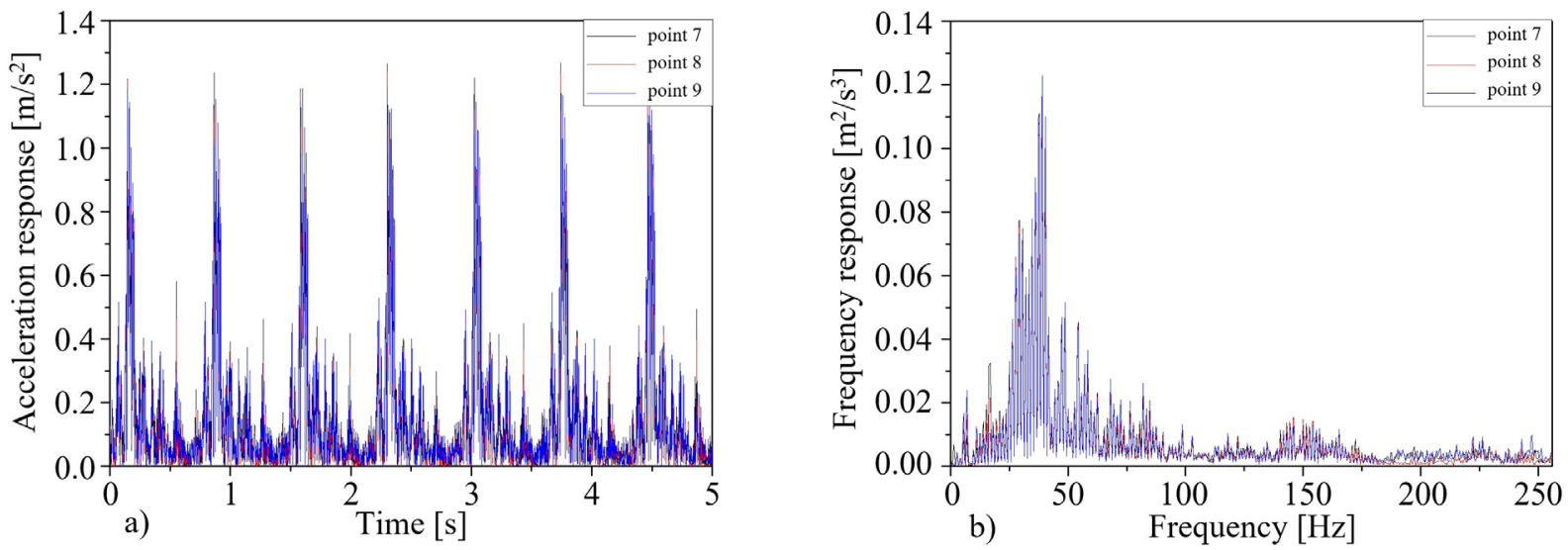

Fig. 18. Response of Z-direction time domain and frequency domain of measurement point at upper cross-beam area (measuring points of 7, 8 and 9); a) time domain response diagram, and b) frequency domain response diagram
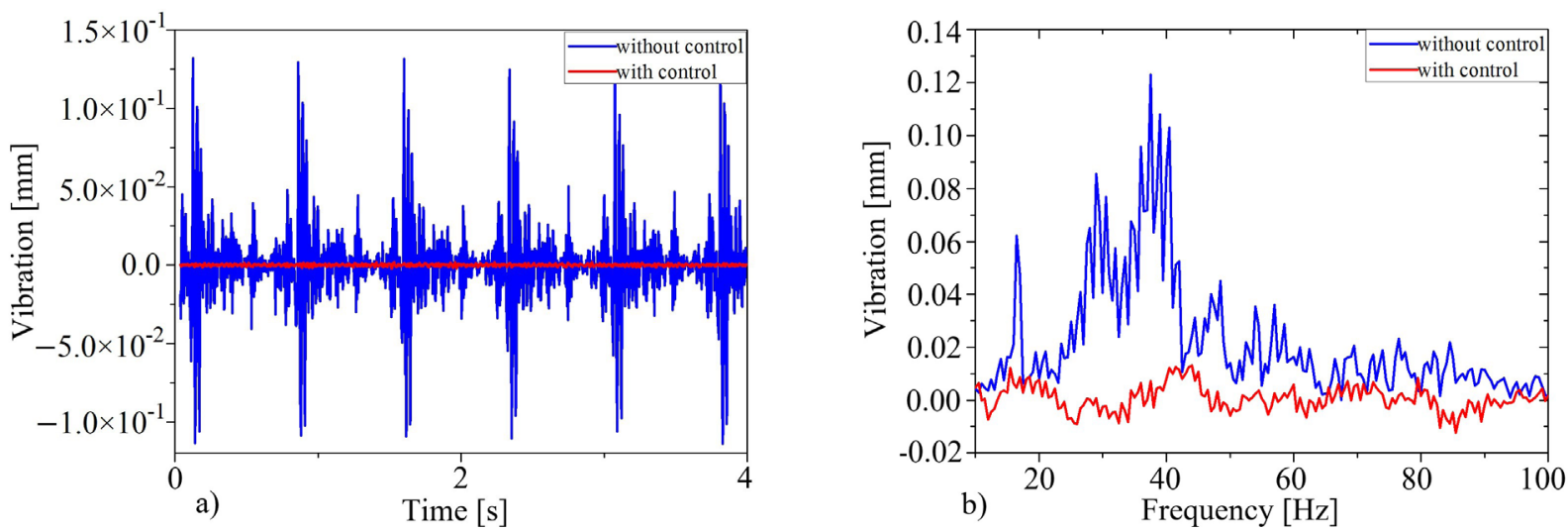

Fig. 19. a) Time domain, and b) frequency domain vibration response with and without control

has been significantly suppressed, and the maximum value of the vibration response has been reduced by more than $95 \%$; the amplitude variation of the vibration response is maintained within the range of $\mathrm{m}$.

For the frequency domain control effect, it can be seen that after controlling the corresponding response of the first three modes, the vibration response amplitude reaches stability very fast, and the maximum value of the vibration response is reduced by more than $80 \%$. At the same time, the convergence speed of the system is very fast after the application of active vibration control.

From the simulation results, it can be seen that the active vibration control applied to the FB press does not suppress the vibration completely. However, the effect of vibration control is very significant, which shows a promising future for the application of the active vibration control method on the FB press.

\section{CONCLUSION}

In this paper, the mechanical vibration model of the fine-blanking press as the controlled object is established, the dynamic model parameters of a mechanical fine-blanking machine are obtained by using finite element analysis and empirical formula. The principle of vibration control of fine blanking press is described, the control algorithm is established, and the adaptive vibration control block diagram of fine blanking press is established.

The self-adaptive feed-forward control is used to simulate the vibration control of the mechanical FB press. The simulation results show that the vibration control effect is good, and the conclusion can be obtained as follows.

The vibration response of the whole machine has been effectively reduced when the active control is applied, in which the time-domain vibration response has been reduced by more than $95 \%$, and the frequency-domain vibration response has been 
reduced by more than $80 \%$, which means that the vibration reduction effect is obvious. Effectively reducing the vibration effect of fine-blanking machine greatly increases the processing accuracy, saves significant amounts of energy, and reduces the energy consumption and defect rate.

\section{ACKNOWLEDGEMENTS}

The authors would like to thank the Fundamental Research Funds for the Central Universities (WUT: 2019III117CG), 111 Project (B17034) and Innovative Research Team Development Program of Ministry of Education of China (No. IRT_17R83) for the supports given to this research and the Huangshi Huali Metal Forming Machine Tool Co., Ltd. for their supports given to experiments.

\section{REFERENCES}

[1] Liu, Y., Tang, B., Hua, L., Mao, H. (2018). Investigation of a novel modified die design for fine-blanking process to reduce the die-roll size. Journal of Materials Processing Technology, vol. 260, p. 30-37, DOl:10.1016/j.jmatprotec.2018.04.029.

[2] Mao, H., Li, S., Liu, Y., Hua, L. (2017). An investigation on the microstructure of the fine-blanked sprocket. The International Journal of Advanced Manufacturing Technology, vol. 90, p. 3171-3185, DOI:10.1007/s00170-016-9589-x.

[3] Xu, Z., Liu, Y., Hua, L., Zhao, X., Guo, W. (2019). Energy analysis and optimization of main hydraulic system in $10,000 \mathrm{kN}$ fine blanking press with simulation and experimental methods. Energy Conversion and Management, vol. 181, p. 143-158, D0l:10.1016/J.enconman.2018.12.012.

[4] Zhao, X., Liu, Y., Hua, L., Mao, H. (2016). Finite element analysis and topology optimization of a $12000 \mathrm{kN}$ fine blanking press frame. Structural and Multidisciplinary Optimization, vol. 54, p. 375-389, Dol:10.1007/s00158-016-1407-4.

[5] Guicking, D. (1990). On the invention of active noise control by Paul Lueg. The Journal of the Acoustical Society of America, vol. 87, p. 2251-2254, Dol:10.1121/1.399195.

[6] Olson, H.G., May, E.G. (1953). Electronic sound absorber. The Journal of the Acoustical Society of America, vol. 25, p. 1130, DOI:10.1121/1.1907249.

[7] Winberg, M., Johansson, S., L Lagö, T.L. (2001). Active control of engine induced noise in a naval application. Pediatric
Pulmonology, vol. 22, no. 4, p. 280-282, D0l:10.1002/10990496(199610)22:43.0.C0;2-K.

[8] Daley, S., Johnson, F.A., Pearson, J.B., Dixon, R. (2004). Active vibration control for marine applications. Control Engineering Practice, vol. 12, no. 4, p. 465-474, Dol:10.1016/\$09670661(03)00135-7.

[9] Shao, C., Zhang, X., Shen, Y. (2000). Active vibration controller designing for high-speed flexible linkage mechanisms. Journal of Mechanical Engineering, vol. 36, no. 12, p. 54-58, DOI:10.3901/JME.2000.12.054.

[10] Li, P. (2012). Theoretical analysis and experiment on active vibration control of a shaft-hull system. Journal of Mechanical Engineering, vol. 48, no. 19, p. 103-108, Dol:10.3901/ JME.2012.19.103.

[11] Zhu, M.G., Jin, G.Y., Feng, N. (2011). Numerical study of active control of interior noise in a structural-acoustic enclosure. Key Engineering Materials, vol. 486, p. 103-106, D0l:10.4028/ www.scientific.net/KEM.486.103.

[12] Belyi, V., Gan, W.-S. (2019). A combined bilateral and binaural active noise control algorithm for closed-back headphones. Applied Acoustics, vol. 160, art. ID 107129, D0l:10.1016/J. apacoust.2019.107129.

[13] Soni, T., Das, A.S., Dutt, J.K. (2020). Active vibration control of ship mounted flexible rotor-shaft-bearing system during seakeeping. Journal of Sound and Vibration, vol. 467, art. ID 115046, DOI:10.1016/j.jsv.2019.115046.

[14] Teo, Y.R., Fleming, A.J. (2015). Optimal integral force feedback for active vibration control. Journal of Sound and Vibration, vol. 356, p. 20-33, Dol:10.1016/j.jsv.2015.06.046.

[15] Park, Y.-M., Kim, K.-J. (2013). Semi-active vibration control of space truss structures by friction damper for maximization of modal damping ratio. Journal of Sound and Vibration, vol. 332, no. 20, p. 4817-4828, D0l:10.1016/j.jsv.2013.04.032.

[16] Sun, W., Zhang, F., Luo, S., Wang, H. (2017). Simulation analysis of adaptive active vibration control. Noise and Vibration Control, vol. 37, p. 23-28. (in Chinese)

[17] Beredugo, Y.0., Novak, M. (2011). Coupled horizontal and rocking vibration of embedded footings. Canadian Geotechnical Journal, vol. 9, no. 4, p. 477-497, D0l:10.1139/ t72-046.

[18] Novak, M. (2010). Effect of soil on structural response to wind and earthquake. Earthquake Engineering \& Structural Dynamics, vol. 3, no. 1 p. 79-96, D0l:10.1002/ eqe.4290030107.

[19] Novak, M. (2011). Foundations for shock-producing machines. Canadian Geotechnical Journal, vol. 20, no. 1, p. 141-158, DOI:10.1139/t83-013. 